\title{
Cross-cultural adaptation and validation of the Spanish version of the American Academy of Orthopaedic Surgeons-Foot and Ankle Module (AAOS-FAMsp)
}

\author{
Manuel González-Sánchez ${ }^{*}$, Esther Velasco-Ramos², Maria Ruiz-Muñoz ${ }^{3}$ and Antonio I. Cuesta-Vargas ${ }^{4,5}$
}

\begin{abstract}
Background: The current study performed a cross-cultural adaptation to Spanish and examined the internal and external validation of the AAOS-FAM questionnaire.

Methods: A direct translation (English to Spanish) and a reverse translation (Spanish to English) were performed by two independent professional native translators. Cronbach's a coefficients were calculated to analyse the internal consistency of the measure. The factor structure and construct validity were analysed after extraction by maximum likelihood (EML); extraction was necessary if the following three requirements were met: accounting for $\geq 10 \%$ of variance, Eigenvalue $>1.0$ and a scree plot inflexion point. The standard error of measurement and minimal detectable change 90 (MDC90) were calculated. Criterion validity was calculated by analysing the correlation between the American Academy of Orthopaedic Surgeons-Foot and Ankle Module (Spanish version) (AAOS-FAMsp) and Spanish versions of the questionnaires FFI and FHSQ.
\end{abstract}

Results: Regarding internal consistency, Cronbach's a was 0.877, and in the test-retest analysis, the ICC ranged between 0.899 and 0.942. Error measures were calculated by MDC90 and SEM, which showed values of 3.444 and $1.476 \%$, respectively. The analysis demonstrated a goodness of fit chi-squared value of $803.166(p<0.001)$. For criterion validity, the correlation value with FFIsp was $r=0.837(p<0.01)$, while the FHSQsp correlation values with different scales ranged from $r=0.206$ ( $p<0.01$ ) (physical activity) to $r=0.665$ ( $p<0.01$ ) (pain).

Conclusions: The results indicate that AAOS-FAMsp has satisfactory psychometric properties, facilitating the inclusion of Spanish-speaking individuals into both research and clinical practice.

Keywords: Foot, Patient reported outcome measures, Assessment, Spanish version, Validation

\section{Background}

In the last 20 years, patient reported outcome measures (PROM) have emerged as an important way to assess and monitor patients and currently are widely used in clinical practice and research $[1,2]$. These instruments are inexpensive, easy to use and specific and reliable tools. They facilitate the determination of a patient's health and functional status and the interpretation of results for

\footnotetext{
* Correspondence: mgsanche@ujaen.es

${ }^{1}$ Health Science Faculty, Department of Health Science, University of Jaén,

Campus de las Lagunillas SN. Ed.B3 - Despacho 066, 23071 Jaén, Spain

Full list of author information is available at the end of the article
}

clinicians, researchers and patients regarding a patient's symptoms, capabilities and/or functioning $[1,3,4]$.

Given the structure and function of the foot, any problematic condition in the foot may have a profound negative impact on a patient's quality of life and function [5]. With the intention of assessing the impact of foot problems in a patient, the American Academy of Orthopaedic Surgeons developed a specific module for the subjective assessment of changes in the foot, i.e. the Foot and Ankle Module (AAOS-FAM) [6]. This questionnaire has two scales, the Global Foot and Ankle Scale and the Foot Comfort Scale, comprised of 25 items 
in total, with a retest reliability between 0.79 and 0.99 [6]. Until now, the AAOS-FAM questionnaire has not been a translation or culturally adapted into Spanish, one of the five most widely spoken languages in the world [7, 8] and an official language of the United Nations [9]. A cultural adaptation and validation of the AAOS-FAM Spanish questionnaire was conducted in this study to facilitate the collection of clinical data from Spanish-speaking individuals and to help improve the standardisation of data collection in clinical research and treatment throughout the country.

The aim of this study was to perform a cross-cultural adaptation to Spanish and to examine the internal and external validation of the AAOS-FAM questionnaire, with the intention of facilitating the inclusion of Spanish-speaking individuals into both research and clinical practice.

\section{Methods \\ Design}

This observational study was conducted with patients recruited from three public and private podiatric clinics in southern Spain. One hundred and ninety-three (193) patients (99 women and 94 men) with a mean age of $55.49( \pm 16.10)$ years participated in the present study (Table 1). The inclusion criteria for the participants were as follows: native Spanish speaker, aged 18 years old or older, having an altered foot that requires treatment and able to walk independently. Participants with a cognitive impairment of any aetiology that prevented them from completing the questionnaires independently were excluded from the present study.

Table 1 Descriptive anthropometric data of the sample

\begin{tabular}{lrrrrr}
\hline & & Mean & SD & Minimum & Maximum \\
\hline Age (years) & 55.49 & 16.10 & 21 & 88 \\
Weight (kg) & 61.22 & 9.37 & 48.22 & 94.34 \\
Height (cm) & 167.70 & 9.53 & 151.30 & 187.20 \\
BMI (kg/m²) & 22.95 & 2.19 & 19.68 & 31.44 \\
Hours weekly's & 45.76 & 6.91 & 20 & 65 \\
standing & & & & & \\
$\mathrm{N}$ & 193 & & & \\
Gender (female/male) & & $99 / 94$ & & & \\
Education level & Elementary & 49 & & & \\
& Secondary & 86 & & & \\
& University & 47 & & & \\
& Master/ & 11 & & & \\
& PhD & & & & \\
Laterality (right/left) & & $158 / 35$ & & & \\
\hline
\end{tabular}

\section{Translation and transcultural adaptation of AAOS-FAM to} AAOS-FAMsp

The process of translating the original AAOS-FAM to the American Academy of Orthopaedic Surgeons-Foot and Ankle Module (Spanish version) (AAOS-FAMsp) questionnaire was carried out in different phases which are summarised in Fig. 1. Direct translation (English to Spanish) and the reverse translation (Spanish to English) were performed by two independent professional native translators. With the aim of ensuring the conceptual equivalence of the terms used, a translation process was performed, as recommended by the literature [10-12].

\section{Data collection}

Between 1 February 2015 and 31 May 2015, all subjects included as participants completed the following questionnaires: AAOS-FAMsp, Foot Function Index (FFI) and Foot Health Status Questionnaire (FHSQ). In order to calculate the reliability of the AAOS-FAMsp, this questionnaire was completed a second time 4 days later. This period of time was used to ensure the condition of the participants had not changed between measurements [13].

The AAOS-FAM consists of 25 questions comprising two scales: the Global Foot and Ankle Scale and the Foot Comfort Scale. The first of the 20-item scales is used to test foot function, inflammation, pain and stiffness, which generated a single score between 0 and 100 . The second scale, consisting of five questions, is used to assess comfort in terms of wearing shoes (with a yes or no for each type), which generated a scale ranging from 0 to $100(0=$ poor outcome and $100=$ the best possible outcome) [6]. The two scales are combined to provide an index ranging from 0 to 100 . We weighed each scale in the final score based on the number of items: Global Foot and Ankle Scale 80 \% (20 items) and Foot Comfort Scale $20 \%$ (five items) [6].

The original version of the FFI questionnaire consists of 23 questions [14, 15]. Each question is answered on a visual analogue scale, ranging from 0 to 9 . If patients cannot respond to any question, they are instructed to leave it blank and it is not included in the final score of the questionnaire [14-16]. The final result is offered on a scale from 0 to 100 , in which all the questions are summed and then divided by 207 (the highest possible score, i.e. $23 \times 9$ ) and multiplied by 100 and then rounded up, if necessary, to give an integer between 0 and 100 [16]. The cross-cultural adaptation of the Spanish FFI questionnaire was validated and published by Paez-Moguer et al. (2013) [16].

The FHSQ is an instrument designed to measure the quality of life related to the health of the feet [17-19]. The 19 questions evaluate four domains of foot health: pain, function, general health and footwear. Each is rated on a Likert (numerical) style $0-100$ scale, where 0 is the 


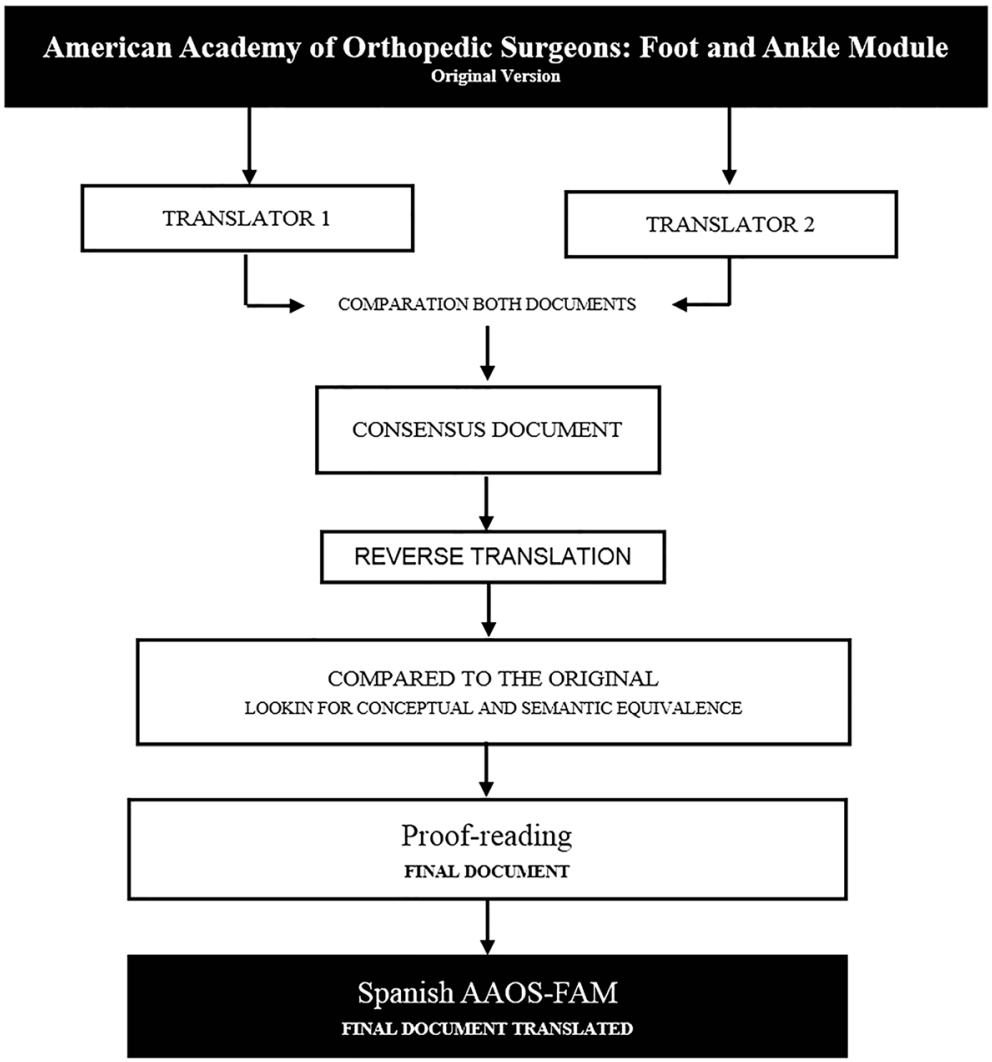

Fig. 1 Flowchart of the development of AAOS-FAMsp from the original version

worst health status and 100 indicates the best health status. This was validated by Bennett and Patterson to evaluate the effectiveness of surgical and conservative treatment of diseases involving the skin and nails, as well as neurological, musculoskeletal and orthopaedic disorders [17-19]. Spanish cross-cultural adaptation of the FHSQ questionnaire was validated and published by Cuesta-Vargas et al. (2013) [17].

\section{Data analysis}

A descriptive analysis of the anthropometric variables and the characteristics of participants was conducted. The Kolmogorov-Smirnov test was used to analyse the distribution and normality of the sample. Cronbach's $\alpha$ coefficients were calculated to analyse the internal consistency of measures by classifying the values according to the following scale: Cronbach's $\alpha \leq 0.40$ (poor), $0.60>$ Cronbach's $\alpha>0.40$ (moderate), $0.80>$ Cronbach's $\alpha \geq 0.60$ (good) and Cronbach's $\alpha \geq 0.80$ (excellent) [20]. To analyse whether item performance was similar between men and women, a comparison of the variables between genders was conducted. All variables presented a parametric distribution, and for this reason, Student's $t$ test was used to calculate the differences between groups.
The factor structure and construct validity were analysed after extraction by maximum likelihood (EML); extraction was necessary if the following three requirements were met: accounting for $>10 \%$ of variance, Eigenvalue $>1.0$ and a scree plot inflexion point.

The formula $\mathrm{SEM}=\mathrm{s} \sqrt{1-r}$ was used to calculate the standard error of measurement (SEM), where $s$ is the standard deviation (SD) of the test score for both measurements (time 1 and 2) and $r$ is the reliability coefficient for the test and interclass correlation (ICC) between test and retest values.

Following the analysis described by Stratford [21], the minimal detectable change 90 (MDC90) was used to measure the sensitivity or measurement error. The formula used for the calculation was:

$$
\mathrm{MDC} 90=\mathrm{SEM} \times \sqrt{2 \times 1.65} .
$$

Criterion validity was calculated by analysing the correlation between the AAOS-FAMsp and Spanish versions of the questionnaires FFI [16] and FHSQ [17]. The Pearson correlation coefficient was interpreted according to the following scale: $r \leq 0.49$ (poor), $0.50 \leq r \leq 0.74$ (moderate) and $r \geq 0.75$ (strong) [22]. 
The minimum power required to develop strengthrelated criterion validity of the AAOS-FAMsp indicated a minimum number of 108 subjects, calculated for a $15 \%$ attrition rate with $p<0.05$ [12]. The statistical analyses were performed using the statistical analysis programme SPSS (v.17.0).

\section{Results}

The AAOS-FAM was translated into Spanish and culturally adapted to provide the new AAOS-FAMsp (available in Additional file 1). Table 1 shows the descriptive data of the sample, which included anthropometric data and the number of hours the participant stands during the week. The average value of the AAOS-FAMsp was 45.66 $( \pm 7.38)$; the mean values of the respective scales were $46.02( \pm 8.43)$ (Global Foot and Ankle Scale) and 44.20 $( \pm 8.25)$ (Foot Comfort Scale). No significant gender differences emerged when comparing the responses per item. For internal consistency, Cronbach's $\alpha$ was 0.877 , and in the test-retest analysis, the ICC ranged between 0.899 and 0.942 . Error measures were calculated by MDC90 and SEM, with values of 3.444 and $1.476 \%$, respectively.

Based on the values observed in Bartlett's test of sphericity $(p<0.001)$ and the Kaiser-Meyer-Olkin values (0.816), the correlation matrix of the AAOS-FAMsp was deemed adequate for EML. Figure 2 shows the scree plot, where a two-factor solution can be observed. Importantly, there were five factors that had Eigenvalues $>1.0$, explaining $67.411 \%$ of the total variance; however, they did not explain more than $10 \%$ of the variance, meaning they could not be extracted. In the analysis of the loaded factors, not all the items loaded in the same way for each of the extracted factors (Table 2). Particularly significant were questions $2,5,9,10,19,21,22$ and 23 , which did not load on either extracted factor, indicating that they can be removed from the questionnaire. The analysis demonstrated a goodness of fit chi-squared value of 803.166 $(p<0.001)$.

For criterion validity, the correlation value with FFIsp was $r=0.837 \quad(p<0.01)$, while the FHSQsp correlation values with different scales ranged from $r=0.206(p<0.01)$ (physical activity) to $r=0.665(p<0.01)$ (pain) (Table 3 ). Moreover, the higher correlation occurred between each of the subscales as well as with the final score of AAOSFAMsp.

\section{Discussion}

The process of translating and culturally adapting the AAOS-FAMsp ensures the conceptual equivalence of terms used between the original questionnaire and the final version of the AAOS-FAMsp, facilitating its introduction and use among native speakers of the second most widely spoken language in the world. In addition, an analysis of the psychometric properties of the questionnaire, including the criterion validity, construct validity, internal consistency and reliability of the measurement was performed, and the authors found optimal psychometric properties as well as high internal consistency and reliability with a strong correlation with FFIsp. These results indicate that it can be used for assessment and monitoring among Spanish speakers to facilitate obtaining

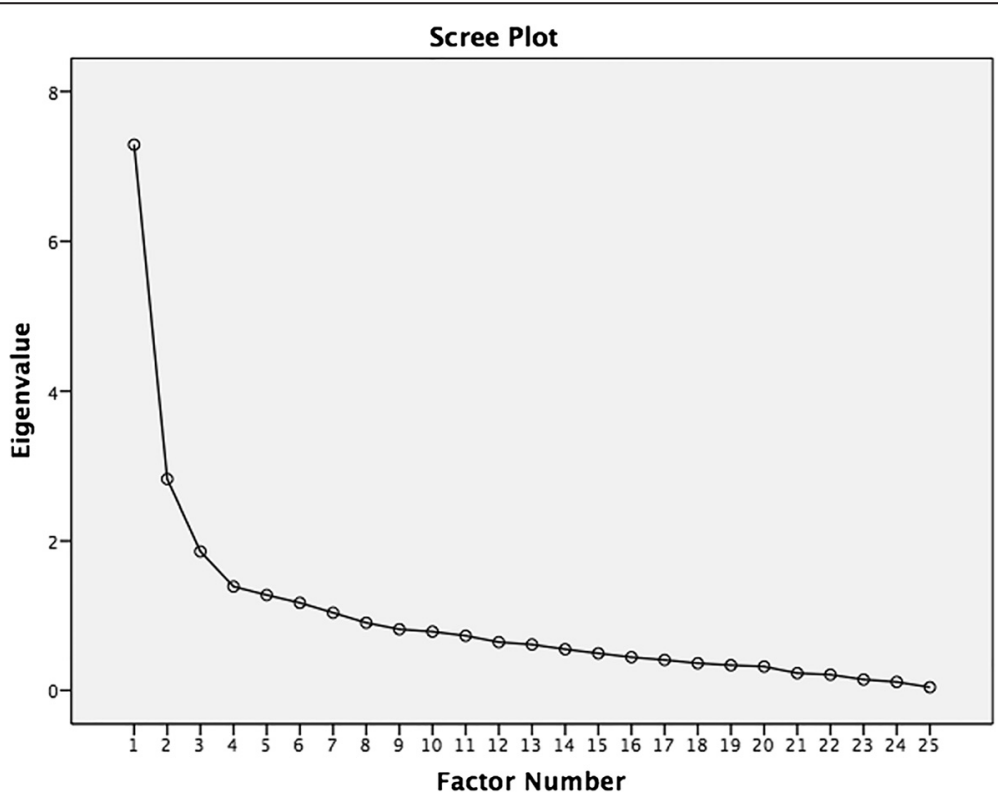

Fig. 2 Scree plot of the exploratory factor analysis: two-factor solution 
Table 2 Load distribution of the different items on the factors identified following exploratory factor analysis

\begin{tabular}{|c|c|c|c|}
\hline & & Factor & \\
\hline & & 1 & 2 \\
\hline P7 & Did foot ankle give way during strenuous activity & 0.947 & -0.139 \\
\hline P8 & Did foot ankle give way during moderate activity & 0.971 & -0.131 \\
\hline P13 & Pain when doing strenuous activity & 0.729 & 0.039 \\
\hline P14 & Pain when doing moderate activity & 0.734 & 0.172 \\
\hline P1 & During the past week how stiff was foot ankle & -0.028 & 0.484 \\
\hline P3 & Pain when walking on uneven surfaces & 0.388 & 0.700 \\
\hline P4 & Pain when walking on flat surfaces & 0.219 & 0.775 \\
\hline P6 & Pain when lying in bed at night & 0.292 & 0.428 \\
\hline P11 & How much trouble with balance during the past week & 0.263 & 0.416 \\
\hline P12 & How difficult was it to put on or take off socks stockings & 0.369 & 0.437 \\
\hline P15 & Pain when doing light activity & 0.335 & 0.635 \\
\hline P16 & Pain when standing for an hour & 0.366 & 0.487 \\
\hline P17 & Pain when standing for a few minutes & 0.215 & 0.569 \\
\hline P18 & How much difficulty walking on uneven surfaces & 0.423 & 0.567 \\
\hline P20 & Can wear most shoes & 0.136 & 0.398 \\
\hline P24 & How much did ankle foot interfere with normal work & 0.211 & 0.727 \\
\hline P25 & How much did ankle foot interfere with life & 0.246 & 0.750 \\
\hline P2 & During the past week, how swollen was foot ankle & 0.130 & 0.249 \\
\hline P5 & Pain when going up or down stairs & 0.020 & 0.341 \\
\hline P9 & Did foot ankle give way during light activity & 0.126 & 0.170 \\
\hline P10 & Which statements best describes your ability to get & 0.242 & 0.254 \\
\hline P19 & Can wear any shoe & 0.207 & 0.300 \\
\hline P21 & Can wear sneakers walking casual shoes & 0.064 & 0.224 \\
\hline P22 & Can wear orthopaedic prescription shoes & -0.074 & 0.020 \\
\hline P23 & Can wear all shoes & 0.190 & 0.252 \\
\hline
\end{tabular}

Table 3 Correlation matrix between AAFOS-FAMsp and subscales as well as FHSQ subscales and FFI

\begin{tabular}{|c|c|c|c|c|}
\hline & & AAOS-FAMsp & Global foot and ankle scale & Shoe comfort scale \\
\hline \multirow[t]{3}{*}{ AAOS-FAMsp } & AAOS FAMsp & 1 & & \\
\hline & Global Foot and Ankle Scale & $0.977^{* * *}$ & 1 & \\
\hline & PRE Shoe Comfort Scale & $0.477^{* *}$ & $0.277^{*}$ & 1 \\
\hline \multirow[t]{8}{*}{ FHSQ subscales } & FHSQ shoe & $0.545^{*}$ & $0.428^{*}$ & $0.690^{* * *}$ \\
\hline & FHSQ foot function & $0.622^{* * *}$ & $0.605^{*}$ & $0.310^{* * *}$ \\
\hline & FHSQ foot pain & $0.665^{* * *}$ & $0.653^{*}$ & $0.304^{*}$ \\
\hline & FHSQ GFH & $0.596^{* * *}$ & $0.598^{*}$ & $0.219^{*}$ \\
\hline & FHSQ general health & $0.426^{* *}$ & $0.434^{* *}$ & 0.131 \\
\hline & FHSQ physical activity & $0.206^{*}$ & $0.216^{*}$ & 0.035 \\
\hline & FHSQ social capacity & $0.409^{* *}$ & $0.402^{* *}$ & $0.187^{*}$ \\
\hline & FQSQ vigour & $0.298^{*}$ & $0.337^{* *}$ & -0.048 \\
\hline $\mathrm{FFI}$ & & $0.837^{* * *}$ & $0.799 * * *$ & $0.474^{*}$ \\
\hline
\end{tabular}


clinical results of high quality for the evaluation of the foot-ankle joint. Therefore, the aim of this study was achieved.

The process of adapting the Spanish AAOS-FAM was conducted following suggestions in the literature [11, 12] and the procedure developed in previous studies that adapted Spanish-specific questionnaires for different body parts such as the upper limbs [3], back [10], lower limbs [1] or ankle and foot [16, 17], using independent and native translators who assured the equivalence of the terms used in the original questionnaire. Cross-cultural adaptation of the AAOS-FAMsp allows clinicians to use this tool to assess the foot-ankle region.

An exploratory factor analysis was performed with the results of the AAOS-FAMsp. After conducting the exploratory factor analysis, not all items loaded on the factor model, as indicated by the questionnaire score (questions: 1-18, 24, 25 (Global Foot and Ankle Scale) and 19-23 (Foot Comfort Scale)) [6]. In addition, there were some items that clearly did not load on any of the factors that had originally been allocated for the calculation of the two subscales of the AAOS-FAMsp (Global Foot and Ankle Scale and Foot Comfort Scale), as shown in Table 2. However, a confirmatory factor analysis was not performed, as our study did not meet the minimum sample size (10 subjects per item analysed) or the optimal sample size (20 subjects per item analysed) necessary to ensure reliable results [23].

The AAOS-FAMsp demonstrated excellent internal consistency; Cronbach's $\alpha$ was 0.877 , and the test-retest (ICC) per item ranged between 0.899 and 0.942. Although both had excellent Cronbach's $\alpha$, the value of AAOSFAMsp (0.877) was slightly higher than the original version (0.83) [6]. However, the test-retest values were consistent between the two versions (0.899-0.942 for AAOS-FAMsp and 0.92 for the original AAOS-FAM [6]).

The AAOS-FAMsp version used the Spanish versions of the FFI and FHSQ questionnaires for criterion validity, while the original version that performed the analysis used the Lower Limb Core questionnaire and SF-36 Physical Health as references. This was based on the classification made by Field [22]. The correlation with FFIsp was strong $(r=0.837)$, ranging from poor $(r=0.206$ (physical activity)) to moderate $(r=0.665$ (pain)) in the FHSQsp subscales (Table 3), whereas the original version presented a moderate correlation $(r=0.56)$ with the SF-36 and a strong correlation $(r=0.97)$ with the Lower Limb Core questionnaire [6].

This study was developed following recommendations in the literature regarding the number of subjects required to conduct a psychometric analysis of the questionnaire, where a minimum of five subjects per item under review is required. The AAOS-FAMsp consists of 25 questions, so a minimum number of 125 subjects would be required; this study included 193 participants [24]. However, this study had some limitations, as not all items loaded onto the two factors described within the original questionnaire (Global Foot and Ankle Scale and Shoe Comfort Scale), so future studies could develop a modified version of the AAOS-FAMsp according to the factors identified in this study. Moreover, no psychometric analyses of variables measured longitudinally, such as sensitivity to change and responsiveness, were presented. It is also important to consider not only the Spanish spoken in Spain, so it would be important for future studies to include Hispanic/Latino speaking participants to resolve any cultural differences with Spanish participants. Finally, the questionnaires were always provided in the same order, which may be a potential source of bias.

\section{Conclusions}

The AAOS-FAMSp demonstrated high internal consistency, reliability and criterion validity. It is an instrument that can be introduced into the Spanish-speaking environment to be used by clinicians and researchers as a tool to assess and monitor their patients.

The AAOS-FAM questionnaire was translated and cross-culturally adapted to Spanish. The psychometric properties of the AAOS-FAMsp were reported, indicating satisfactory and consistent results with the original version. However, the factor structure was slightly different than the original AAOS-FAM questionnaire.

\section{Additional files}

Additional file 1: The AAOS-FAM was translated into Spanish and culturally adapted to provide the new AAOS-FAMsp. (PDF $123 \mathrm{~kb}$ )

Additional file 2: Raw data base containing descriptive results variables. (SAV $14 \mathrm{~kb}$ )

\section{Abbreviations}

AAOS-FAM, American Academy of Orthopaedic Surgeons-Foot and Ankle Module; AAOS-FAMsp, American Academy of Orthopaedic Surgeons-Foot and Ankle Module (Spanish version); EML, extraction by maximum likelihood: FFI, Foot Function Index; FHSQ, Foot Health Status Questionnaire; ICC, interclass correlation; MDC90, minimal detectable change 90; PROM, patient reported outcome measures; SD, standard deviation; SEM, standard error of measurement

\section{Acknowledgements}

The authors would like to thank all who took part in the intervention and enabled the study to take place.

\section{Funding}

Not applicable.

\section{Availability of data and materials}

The raw database is available for all potentials readers. Please, find it as supplementary material.

Authors' contributions

MG-S participated in the conception and design of the study and in the data collection, analysis and interpretation of the data and helped to draft the manuscript. EV-R participated in the data collection, analysis and interpretation of the data and drafted the manuscript. MR-M participated in the conception of 
the study, analysis and interpretation of the data and helped to draft the manuscript. AIC-V participated in the analysis and interpretation of the data, helped to draft the manuscript and supervised the development of the study. All authors read and approved the final manuscript.

\section{Authors' information}

Manuel González-Sánchez PhD is a Professor at the University of Jaén and a physiotherapist. Esther Velasco Ramos MSc is a podiatrist. María Ruiz-Muñoz PhD is a Professor at the University of Málaga and a podiatrist. Antonio I. Cuesta-Vargas PhD is a Senior Lecturer at the University of Málaga, a Professor at the School of Clinical Sciences at Queensland University, Brisbane, Australia, and a physiotherapist.

\section{Competing interests}

The authors declare that they have no competing interests.

\section{Consent for publication}

Not applicable.

\section{Ethics approval and consent to participate}

To be included in the study, participants provided signed informed consent. The study was conducted according to the Ethical Principles for Medical Research Involving Human Subjects, and the data were used according to the Spanish Organic Law of Protection of Personal Data 19/55. The present study was approved by the University of Málaga ethics committee. To ensure the independence of the collected data, the analysis of the data was performed by two blinded and independent investigators.

\section{Author details}

${ }^{1}$ Health Science Faculty, Department of Health Science, University of Jaén, Campus de las Lagunillas SN. Ed.B3 - Despacho 066, 23071 Jaén, Spain. ${ }^{2}$ Health Science Faculty, Universidad de Málaga, Málaga, Spain.

32Departamento de Enfermería y Podología, Instituto de Investigación Biomédica de Málaga (IBIMA), Universidad de Málaga, Málaga, Spain. ${ }^{4}$ Departamento de Psiquiatria y Fisioterapia, Instituto de Investigación Biomédica de Málaga (IBIMA), Universidad de Málaga, Málaga, Spain. ${ }^{5}$ School of Clinical Sciences at Queensland University, Brisbane, Australia.

Received: 24 February 2016 Accepted: 28 June 2016

Published online: 06 July 2016

\section{References}

1. Cuesta-Vargas Al, Gabel CP, Bennett P. Cross cultural adaptation and validation of a Spanish version of the Lower Limb Functional Index. Health Qual Life Outcomes. 2014;12:75. doi:10.1186/1477-7525-12-75.

2. Garratt A. Patient reported outcome measures in trials. BMJ. 2009:338:a2597. doi:10.1136/bmj.a2597

3. Cuesta-Vargas Al, Gabel PC. Cross-cultural adaptation, reliability and validity of the Spanish version of the Upper Limb Functional Index. Health Qual Life Outcomes. 2013;11:126. doi:10.1186/1477-7525-11-126.

4. Forget NJ, Higgins J. Comparison of generic patient-reported outcome measures used with upper extremity musculoskeletal disorders: linking process using the International Classification of Functioning, Disability, and Health (ICF). J Rehabil Med. 2014;46(4):327-34. doi:10.2340/16501977-1784.

5. Kaoulla P, Frescos N, Menz HB. A survey of foot problems in communitydwelling older Greek Australians. J Foot Ankle Res. 2011;4(1):23. doi:10.1186/1757-1146-4-23.

6. Johanson NA, Liang MH, Daltroy L, Rudicel S, Richmond J. American Academy of Orthopedic Surgeons lower limb outcomes assessment instruments. Reliability, validity, and sensitivity to change. J Bone Joint Surg Am. 2004;86-A(5):902-9.

7. Instituto Cervantes. Resumen del informe 2013 «El español, una lengua viva» http://www.cervantes.es/sobre_instituto_cervantes/prensa/2013/ noticias/diae-resumen-datos-2013.htm [Accessed 20 Jul 2015].

8. Ruiz Zambrana J. La situación actual de la lengua española en el mundo. Contribuciones a las Ciencias Sociales, 2009. available in: www.eumed.net/ rev/cccss/05/jrz.htm [Accessed 9 Mar 2015].

9. UN. New York: 2014. available in: http://www.un.org/es/sections/about-un/ official-languages/index.html [Accessed 20 Jul 2015].
10. Cuesta-Vargas Al, González-Sánchez M. Spanish version of the screening Örebro musculoskeletal pain questionnaire: a cross-cultural adaptation and validation. Health Qual Life Outcomes. 2014;12:157. doi:10.1186/s12955-014-0157-5.

11. Mokkink LB, Terwee CB, Patrick DL, Alonso J, Stratford PW, Knol DL, Bouter LM, de Vet HC. The COSMIN study reached international consensus on taxonomy, terminology, and definitions of measurement properties for health-related patient-reported outcomes. J Clin Epidemiol. 2010;63(7):737-45. doi:10.1016/j.jclinepi.2010.02.006

12. Muñiz J, Elosua P, Hambleton RK. International test commission guidelines for test translation and adaptation: second edition. Psicothema. 2013;25:151-7.

13. Vet HC, Ostelo RW, Terwee CB, van der Roer N, Knol DL, Beckerman H, Boers M, Bouter LM. Minimally important change determined by a visual method integrating an anchor-based and a distribution-based approach. Qual Life Res. 2007;16:131-42.

14. Budiman-Mak E, Conrad KJ, Mazza J, Stuck RM. A review of the foot function index and the foot function index-revised. J Foot Ankle Res. 2013;6(1):5. doi:10.1186/1757-1146-6-5.

15. Budiman-Mak E, Conrad K, Stuck R, Matters M. Theoretical model and Rasch analysis to develop a revised Foot Function Index. Foot Ankle Int. 2006;27(7):519-27.

16. Paez-Moguer J, Budiman-Mak E, Cuesta-Vargas Al. Cross-Cultural adaptation and validation of the Foot Function Index to Spanish. Foot Ankle Surg. 2014;20(1):34-9. doi:10.1016/j.fas.2013.09.005. Epub 2013 Nov 16.

17. Cuesta-Vargas A, Bennett P, Jimenez-Cebrian AM, Labajos-Manzanares MT. The psychometric properties of the Spanish version of the Foot Health Status Questionnaire. Qual Life Res. 2013;22(7):1739-43. doi:10.1007/ s11136-012-0287-3.

18. Bennett PJ, Patterson C. The Foot Health Status Questionnaire (FHSQ): a new instrument for measuring outcomes of foot care. Australasian J Podiatr Med. 1998;32:55-9.

19. Bennett PJ, Patterson C, Wearing S, Baglioni T. Development and validation of a questionnaire designed to measure foot-health status. J Am Podiatr Med Assoc. 1998:88:419-28.

20. Shrout PE, Fleiss JL. Intraclass correlations: uses in assessing rater reliability. Psychol Bull. 1979;86:420-8.

21. Stratford PW. Getting more from the literature: estimating the standard error of measurement from reliability studies. Physiother Can. 2004;56:27-30.

22. Field A. Discovering statistics using SPSS. London: SAGE Publications Ltd; 2005

23. Costello AB, Osborne JW. Best practices in exploratory factor analysis: four recommendations for getting the most from your analysis. Pract Assess, Res Eval. 2005;10(7):1-9.

24. Kass RA, Tinsley HEA. Factor analysis. J Leisure Res. 1979;11:120-38.

\section{Submit your next manuscript to BioMed Central and we will help you at every step:}

- We accept pre-submission inquiries

- Our selector tool helps you to find the most relevant journal

- We provide round the clock customer support

- Convenient online submission

- Thorough peer review

- Inclusion in PubMed and all major indexing services

- Maximum visibility for your research

Submit your manuscript at www.biomedcentral.com/submit 